\title{
Assessing Spatiotemporal Characteristics of Drought based on SPI in Mongolia Plateau
}

\author{
Enliang Guo ${ }^{1,2}$, Yulong Bao ${ }^{1,3}$, Ren Bu ${ }^{1,2, *}$, Yuhai Bao ${ }^{1,2,3}$, Quan Lai ${ }^{1,2,3}$, \\ Mei Yong ${ }^{1,2,3}$, Yongfang Wang ${ }^{4}$ \\ ${ }^{1}$ College of Geographical Science, Inner Mongolia Normal University, Huhhot 010022, China \\ ${ }^{2}$ Inner Mongolia Key Laboratory of Disaster and Ecological Security on the Mongolia plateau, \\ Huhhot 010022, China \\ ${ }^{3}$ Inner Mongolia Key Laboratory of Remote Sensing and Geographic Information Systems, \\ Inner Mongolia Normal University, Hohhot 010022, China \\ ${ }^{4}$ Grassland Research Institute, Chinese Academy of Agricultural Science, Huhhot 010022, China
}

\section{基于 SPI 的蒙古高原干旱时空演变特征研究 \\ 郭恩亮 ${ }^{1,2}$, 包玉龙 ${ }^{1,2,3}$, 布仁 ${ }^{1,2, *}$, 包玉海 ${ }^{1,3}$, 来全 ${ }^{1,2,3}$, 咏梅 ${ }^{1,2,3}$, 王永芳 ${ }^{4}$ \\ ${ }^{1}$ 内蒙古师范大学地理科学学院, 内蒙古 呼和浩特, 010022, 中国 \\ 2 内蒙古自治区蒙古高原灾害与生态安全重点实验室, 内蒙古呼和浩特, 010022, 中国 \\ ${ }^{3}$ 内蒙古自治区遥感与地理信息系统重点实验室, 内蒙古 呼和浩特, 010022, 中国 \\ ${ }^{4}$ 中国农业科学院草原研究所, 内蒙古呼和浩特, 010022, 中国}

\begin{abstract}
This study is based on the SPI that was calculated from precipitation data of the TerraClimate dataset during 1958-2017, analysis of spatiotemporal characteristics of drought in Mongolia Plateau using climate trend and Pettit mutation method, the results showed that the Mongolian Plateau get significant drier trend with a rate of $0.155 /$ decade. In spring and autumn, the trend of humidification was observed, while in summer and autumn, the trend of aridity was observed. In the summer, the SPI value showed a significant decrease with a rate of $0.2075 /$ decade; The pixel-by-pixel analysis of the SPI trend found that the proportions of the drought-reduced trends in spring, summer, autumn and winter were $18.47 \%, 95.22 \%$,
\end{abstract}

*通讯作者: guoel1988@imnu.edu.cn
$53.49 \%$, and $4.28 \%$, respectively. It showed a significant aridity insummer, the annual arid area of the Mongolian Plateau accounted for $90.06 \%$; the summer SPI changed more drastically, accounting for $29.39 \%$ of the area. It is mainly located in the central and northern regions of the study area, while the change of SPI in winter is mainly located in the northeast region, accounting for $19.04 \%$.

Keywords: Drought; SPI; Mutation analysis; Trend test; Mongolian Plateau

摘要

本研究基于 TerraClimate 数据集中 1958-2017 年的降水资料计算 SPI 指数, 然 后利用气候倾向率和 Pettitt 突变法对蒙 古高原干旱时空进行特征分析, 结果表明: 蒙古高原以-0.155/ decade 的变化速率呈 现出显著干旱化趋势。春季和秋季有湿润 
化趋势, 而夏季和秋季存在干干旱化趋势。 其中夏季 SPI 值以-0. 2075/ decade 显著减 小, 基于像元尺度分析 SPI 指数的变化趋 势发现, 春夏秋冬季的 SPI 指数呈减少趋 势的比例分别为 $18.47 \% 、 95.22 \% 、 53.49 \%$ 和 $4.28 \%$, 其中夏季呈现出明显干旱化, 蒙古高原全年干旱面积占 $90.06 \%$; 夏季 SPI 指数变化更加剧烈, 所占面积比例为 $29.39 \%$, 主要分布在研究区中部和北部地 区, 冬季 SPI 指数突变点主要位于东北地 区, 所占面积比例为 $19.04 \%$ 。

关键词: 干旱; SPI; 突变分析; 趋势检验; 蒙古高原

\section{1. 前言}

气候变暖是现阶段全球气候变化的主 要特征, IPCC 第五次评估报告指出全球变 暖是冊庸置疑的, 全球表面温度在 $1880-$ 2012 年期间平均增加了 $0.85 \circ \mathrm{C}[1]$, 人类 活动在全球变暖中起到了重要的作用 [2], 其中研究显示气候变化是未来极端干旱暴 露性增加的主要原因 [3]。干旱指标是干旱 监测、预警、风险评估中的关键参数。前 人已对气象干旱指标作了大量的研究, 构 建了大量的气象干旱指标进行干旱的研究, 如综合干旱指数 (CI) $[4] 、 Z$ 指数 $[5]$ 、标 准化降水指数 (SPI) [6]、标准化降水蒸 散指数 (SPEI) [7]、帕尔默干旱指数 (Palmer) [8]等, 并利用这些干旱指标对 全球及区域尺度的干旱时空变化规律进行 了研究, 为我们在理论上的借鉴和实践上 的参考奠定了基础。

蒙古高原我国北方重要的生态屏障, 也是我国开展 “一带一路” 国家发展战略 及建设中蒙俄经济走廊的重要区域之一, 该区面积广阔, 区内生态类型、地貌类型 复杂多样, 由于人类活动和气候变暖的影 响, 造成该地区近年来导致蒙古高原地区 生态环境出现了大面积沙漠化现象, 并且 导致了沙尘暴的频繁发生。由于干旱少雨、 水资源短缺并且时空分布不均匀 [9], 频繁 发生的干旱灾害加剧了沙漠化面积的扩大 和沙尘暴发生的频率和强度。干旱灾害的 发生还引起了一系列的次生生态灾害, 如: 火灾、蝗虫灾害、草地退化等。但是, 现
阶段对于蒙古高原干旱特征的研究较少, 因此, 本研究基于 TerraClimate 数据集中 的降水数据, 利用标准化降水指数 (SPI) 进行蒙古高原干旱时空演变特征的研究, 研究结果有利于了解该地区的干旱灾害形 成原因, 进而可以有针对性的提出干旱灾 害防治对策，对该地区的农牧业发展及生 态环境保护具有非常重要的现实意义。

\section{2. 研究区概况}

蒙古高原属于亚洲内部草原, 广义的 蒙古高原蒙古国全境、我国内蒙古自治区 和甘肃、宁夏和陕西部分地区, 但是在实 际研究过程中, 国内外学者主要按照狭义 蒙古高原边界线进行研究, 即蒙古国全境 和内蒙古全区。蒙古高原位于干旱半干旱 地区, 为典型大陆性气候, 年内降水量主 要集中在 $5^{\sim} 10$ 月, 并且潜在蒸散量远大于 降水量, 造成该区域干旱少雨, 并且冬冷 夏热 $[10]$ 。

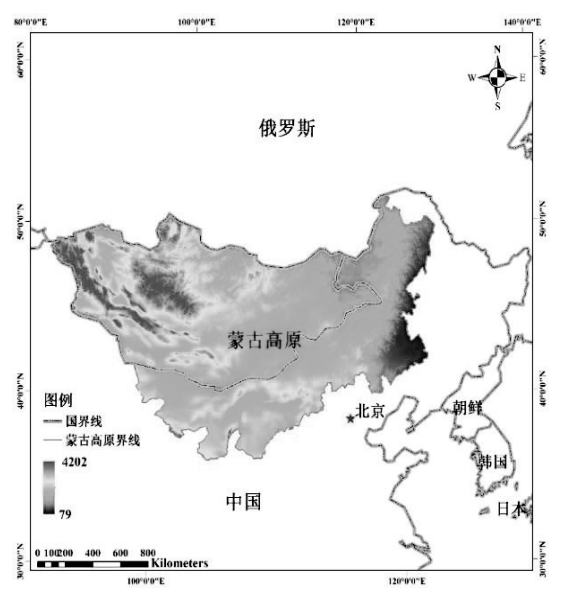

图 1. 蒙古高原区位图

\section{3. 数据源及方法}

\section{1 数据源}

TerraClimate 数据集是 1958-2017 年 全球陆地表面月度气候和气候水量平衡数 据集, 空间分辨率约等于 4 公里 $\left(1 / 24^{\circ}\right)$, 包括最高温、最低温、降水量等数据 [11], 本文利用的是月降水量数据进行 SPI 指数 的计算。 


\section{2 研究方法}

\subsection{1 气候倾向率}

本研究利用气候倾向率分析干旱指数 的变化趋势, 其中 $X_{i}$ 表示 60 年的干旱指数, $t$ 表示 1958-2017 年。计算公式如下:

$$
\mathrm{X}_{i}=a t_{i}+b
$$

式中: $a$ 是回归系数, $b$ 为常数项。 $a$ 和是 $b$ 利用最小二乘法计算得来。

\subsubsection{Pettitt 突变法}

现阶段突变检验有很多种方法, 本研 究选择 Pettitt 突变法, 该方法是非参数 检验方法, 对异常值不明显并且能计算检 验值 $\mathrm{p}$ 值 [12], 计算公式如下所示:

$$
K t=\max _{1 \leq t \leq T}\left|U_{t, T} t\right|=\max \left(\mathrm{K}_{T}^{+}, \mathrm{K}_{T}^{-}\right)
$$

\section{参数信息详见相关参考文献。}

\section{4. 结果分析}

\section{1 趋势分析}

不同时间尺度 SPI 指数对于降水量的响应 程度存在着显著差异, 其中 SPI01 表示的 是由于月降水量变化而引起的旱涝交替现 象 (图 2-a), 而 SPI03 表示的是季节尺度 的变化, 其对于旱涝持续时间的辨识更为 准确 (图 2-b), SPI06 亦是如此, 其表示 的半年内的干湿情况, 而 SPI12 可以识别 旱涝的长期影响及年际变化 (图 2-d)。为 了表征蒙古高原整体的年及季节干旱特征, 本研究选取 SPI03 和 SPI12 进行研究, 其 中根据 SPI 的定义, SPI03 的 5 月、 8 月、 11 月和 2 月代表春夏秋冬四季, SPI12 中 的 12 月 SPI 值表征年度干旱。

利用区域平均月降水量计算 SPI03 和 SPI12, 并统计了 1958-2017 年期间不同干 旱等级的干旱年份 (表 1), 结果表明, 1999 年之后蒙古高原干旱频率明显增加,

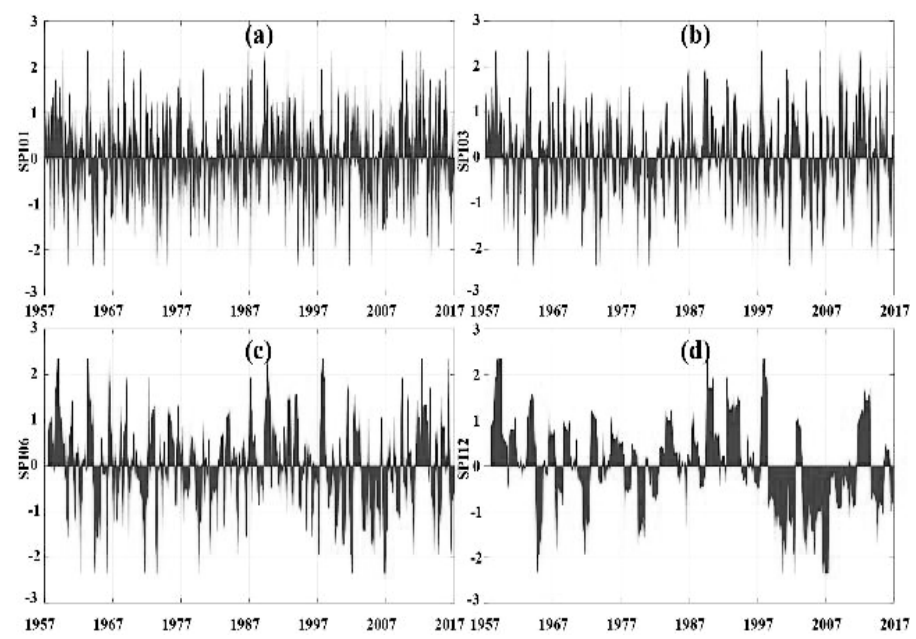

图 2. 蒙古高原不同尺度 SPI 变化趋势图

\begin{tabular}{|c|c|c|c|c|c|c|c|c|c|}
\hline 干旱等级 & & & & & 年份 & & & & \\
\hline 轻旱 & 1978 & 1982 & 1999 & 2006 & 2009 & 2011 & 2014 & 2015 & 2017 \\
\hline 中旱 & 1972 & 1980 & 2000 & 2002 & 2005 & & & & \\
\hline 重旱 & 1965 & 2001 & 2004 & & & & & & \\
\hline 特旱 & 2007 & & & & & & & & \\
\hline
\end{tabular}

表 1 蒙古高原干旱年份统计表 
其中 2007 年发生了特旱现象, 1999-2002 年和 2004-2007 年连续发生干旱现象, 利 用 Pettitt 突变方法还对蒙古高原整体的 不同季节和年度干旱指数的突变年份进行 分析亦说明上述现象, 结果表明除了秋季 干旱指数在 1995 年发生突变以外, 其他季 节和年度指数皆是在 1999 左右出现突变现 象。利用气候倾斜率法计算 1958-2017 年 期间年和季节 SPI 指数的变化趋势可知, 年 SPI 指数以 $-0.1535 /$ decade 的速度呈 现显著性减小趋势, 说明蒙古高原在 19582017 年期间呈现出了干旱化趋势, 而春季 和冬季的 SPI 指数呈现增加趋势, 变化率 分别为 $0.10793 /$ decade 和 $0.192 /$ decade, 其中冬季变化速率通过了 0.05 水平上的显 著性检验, 而夏季的干旱化趋势最为显著, 其以 0. 2075/decade 的速度呈现显著性减 小, 虽然秋季也出现干旱化趋势, 但是变 化趋势（-0.0142/decade）未通过显著性 检验。

\subsection{4 .2 空间趋势分析}

图 4 是利用气候倾斜率法计算并绘制 的蒙古高原年和季节干旱变化趋势空间分 布图, 由图可知, 春季呈现出干旱化趋势 的面积所占比例为 $18.47 \%$, 主要位于蒙古 高原的西部和东北地区, 其中变化速率主 要在 $0^{\sim}-0.075 /$ decade 之间并且未通过 0.05 水平显著性检验 (图 3-a)。夏季 SPI
指数减小趋势的变化速率大且所占比例高, 其中 $95.22 \%$ 的呈现出减小趋势, 包括 $42.76 \%$ 的像元呈显著减小。干旱化最为严 重的区域主要位于蒙古高原中部地区（蒙 古国境内), 而夏季变的相对湿润地区为研 究区的东部和东北地区, 但是未通过显著 性检验图 3-b)。秋季 SPI 指数变化的空间 模式较为明显, 大致呈现出东北干旱化西 南湿润化趋势, 其中干旱化趋势所占比例 为 $53.49 \%$, 仅有 $0.67 \%$ 区域变化显著（图 $3-c)$ 。冬季 SPI 指数主要是呈增加趋势, 所占比例为 $95.72 \%$, 其中 37.13 呈现显著 增加趋势, 说明蒙古高原冬季湿润化趋势 较为明显, 干旱化趋势地区主要是位于东 南区域 (图 3-d)。年 SPI 指数变化趋势空 间分布与夏季类似, 但是干旱化面积所占 比例减少至 $90.06 \%$, 并且干旱化强度相对 夏季也呈减小趋势, 其中 $24.27 \%$ 的区域干 旱化趋势明显（图 3-e)。

\subsection{4 .3 空间突变分析}

本文还利用 Pettitt 突变方法在像元尺度 上进行了年和季节 SPI 指数的突变分析, 由图 5 可知, 春季 SPI 指数突变点全部位 于蒙古国境内且主要集中在北部地区, 像 元个数为 8765 个, 除了 361 个像元是在 1984 发生突变之外, 其余主要发生在 1999 年前后, 其中 $82.48 \%$ 发生在 1999 年。与其 他季节相对, 夏季 SPI 指数的突变所占比
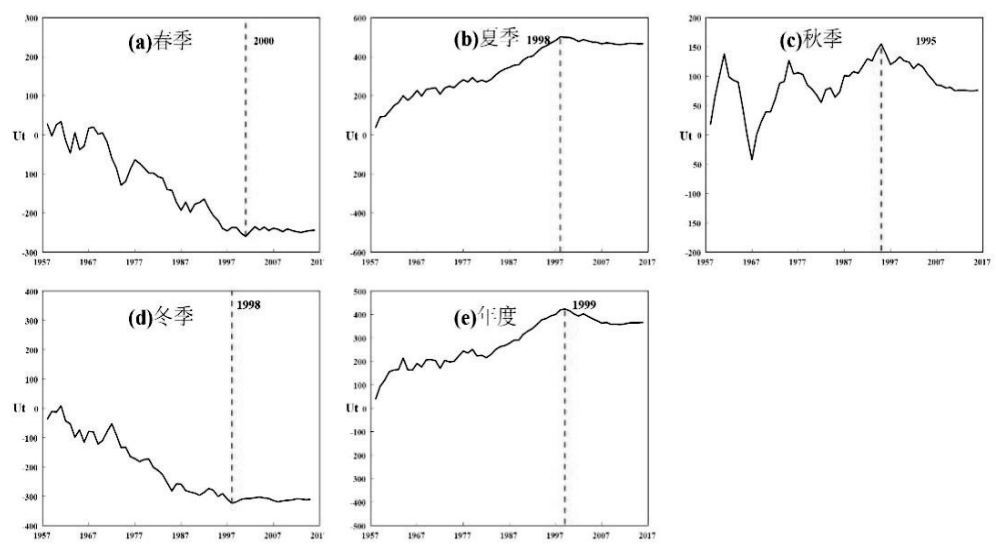

图 3. 蒙古高原年和季节 SPI 指数的 Pettitt 突变检验 


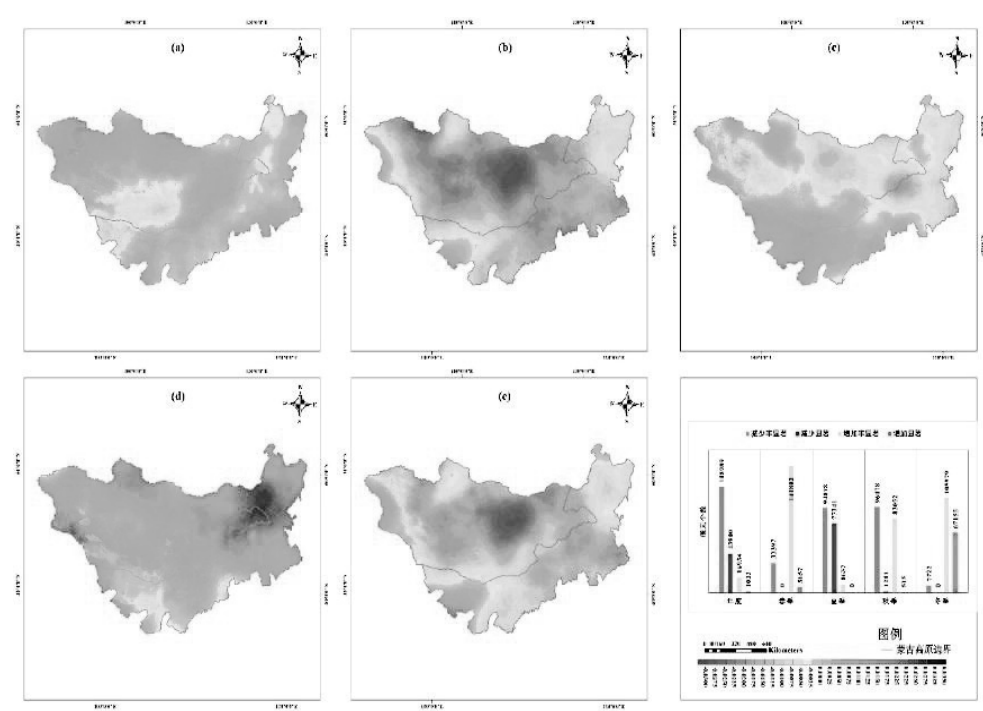

图 4. 蒙古高原年和季节干旱空间变化趋势图

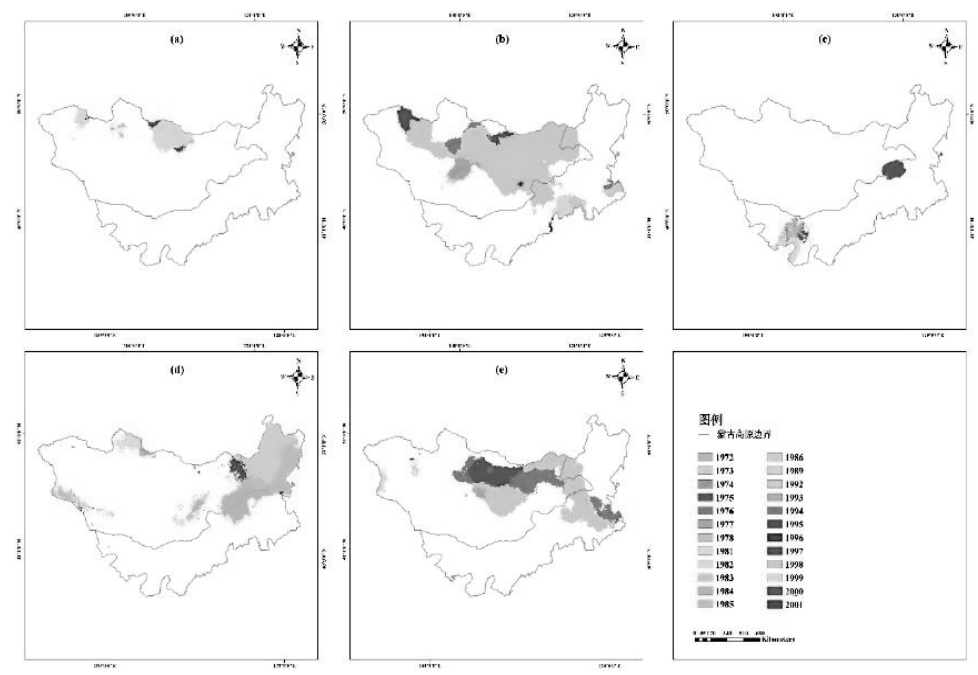

图 5. 蒙古高原年和季节干旱指数突变年份分布图

例做大, 总计 61446 个像元发生了突变现 象, 其中发生在 80 年代之前的有三十三个 像元, 主要是发生在 1998 年, 所占比例为 83. $45 \%$, 空间上主要位于蒙古高原中部和 北部地区。秋季 SPI 仅有 6490 个突变点, 其中主要发生在九十年代, 所占比例高达 $97.66 \%$ 。空间上主要是位于内蒙古西南部 和锡林郭勒盟及与之相近的蒙古国境内。 冬季 SPI 有 34433 个突变点, 其中主要位 于东北地区, 时间上也主要集中在 1984 、
1985 和 1986 年, 全年 SPI 突变点空间分 布与夏季类似, 其中 1998 所占比例为 $55.12 \%$, 总体上看, SPI 像元值发生突变与 变化率的极值空间分布类似。

\section{5. 结论}

本研究基于 TerraClimate 数据集中的 降水数据, 利用标准化降水指数 (SPI) 进 行蒙古高原干旱时空演变特征的研究, 得 到如下结论:

( 1 ) 蒙古高原整体上以 - 
0.1535/decade 的速度呈现干旱化趋势, 而春季和冬季则越来越湿润, 而夏季和秋 季则越来越干旱。

(2) 春夏秋冬四个季节的 SPI 指数呈 减少趋势的比例分别为 $18.47 \%$ 、95.22\%、 $53.49 \%$ 和 $4.28 \%$, 其中夏季呈现出显著干 旱化现象, 全年干旱面积占 $90.06 \%$, 说明 了夏季主导了全年干旱的频率和强度。

(3) 全年 SPI 指数与夏季 SPI 指数的 突变点空间分布类似, 其中发生在 1998 年 的像元数所占比例为 $55.12 \%$, 总体上看, SPI 指数发生突变与变化率的极值空间分布 类似。

\section{Acknowledgements}

This study was supported by the Key Program of National Natural Science Foundation of China (No.61631011), the National Natural Science Foundation of China under Grant (No. 41561099), Science and technology planning project in Inner Mongolia (No. 201702116).

\section{致谢}

本研究由国家自然科学重点项目 (61631011)、国家自然科学基金项目 (41561099) 、内蒙古科技计划项目 （201702116）资助。

\section{参考文献}

[1] Stocker T. Climate change 2013: the physical science basis: Working Group I contribution to the Fifth assessment report of the Intergovernmental Panel on Climate Change. Cambridge University Press, 2014.

[2] Findell K L, Berg A, Gentine P, et al. The impact of anthropogenic land use and land cover change on regional climate extremes. Nature Communications, 2017,8(1). DOI:10.1038/s41467-01701038-w.
[3] Smirnov O, Zhang M, Xiao T, et al. The relative importance of climate change and population growth for exposure to future extreme droughts. Climatic Change, 2016, 138(1-2): 41-53.

[4] Guo E, Liu X, Zhang J, et al. Assessing spatiotemporal variation of drought and its impact on maize yield in Northeast China. Journal of Hydrology, 2017, 553: 231-247.

[5] 齐冬梅, 李跃清, 王莺, 等. 基于 $\mathrm{Z}$ 指数 的四川干旱时空分布特征. 干旱气象, 2017(05):734-744.

[6] 孙仲益, 张继权, 乌兰, 等. 基于 Copula 的洮儿河流域干早特征分析//: 中国灾 害防御协会风险分析专业委员会第六 届年会, 中国内蒙古呼和浩特, 2014.

[7] 张琪, 朱萌, 张继权, 等. 气候变化背景 下吉林干旱风险识别研究//: 中国灾害 防御协会风险分析专业委员会第六届 年会, 中国内蒙古呼和浩特, 2014 .

[8] Liu Y, Zhu Y, Ren L, et al. A multiscalar Palmer drought severity index. Geophysical Research Letters, 2017, 44(13): 6850-6858.

[9] Zhang Q, Yu H, Liu G, et al. The response characteristics of Xilingol Grassland to uneven distribution of precipitation at temporal and spatial scale. Journal of Risk Analysis and Crisis Response, 2016,6(4):206-212.

[10] 张韵婕, 桂朝, 刘庆生, 等. 基于遥感和 气象数据的蒙古高原 1982 2013 年植 被动态变化分析. 遥感技术与应用, 2016(05):1022-1030.

[11] Abatzoglou J T, Dobrowski S Z, Parks S A, et al. TerraClimate, a high-resolution global dataset of monthly climate and climatic water balance from 1958-2015. Scientific Data, 2018,5:170191.

[12] 顾西辉, 张强, 王宗志. 1951-2010 年珠 江流域洪水极值序列平稳性特征研究. 自然资源学报, 2015(05):824-835 